\title{
IGUALDAD DE GÉNERO Y TRANSVERSALIDAD EN LA EDUCACIÓN BÁSICA EN CHIHUAHUA
}

\author{
FAVIOLA MONTOYA \\ SARA TERRY
}

\section{RESUMEN}

E ste documento reporta resultados preliminares del trabajo de investigación dirigido a visibilizar las representaciones sociales que las y los docentes de educación preescolar y primaria poseen sobre la igualdad de género y la transversalidad en el estado de Chihuahua, teniendo como antecedente la igualdad de género como uno de los ocho objetivos del milenio de Naciones Unidas y la implementación de la transversalidad (gender mainstreaming).

Por su parte, el actual Plan Nacional de Desarrollo 2013-2018 establece la igualdad de género como una de sus tres estrategias transversales, lo que implica que el sector educativo tenga la información necesaria y pertinente para poder llegar a acciones concretas en este sentido. Para ello se ha recurrido a los cruces interdisciplinarios entre género, educación y representaciones sociales.

Palabras clave: educación y género, transversalidad e igualdad, educación preescolar y primaria, Chihuahua, docentes 


\section{INTRODUCCIÓN}

Camacho y Watson (2008) identifican a los centros educativos como espacios donde se influye en la construcción de las identidades personales; tienen también por objetivo promover normas sociales y culturales, así como reproducir esquemas de valores. Es por esto que el género como temática de estudio ha tenido el objetivo de desarrollar prácticas que erradiquen la exclusión y construyan espacios donde puedan establecerse relaciones equitativas entre hombres y mujeres, en particular a edades tempranas, ya que los individuos incursionan cada vez a menor edad en los sistemas de educación básica y su permanencia en estas instituciones implica por lo menos un tercio de sus actividades diarias. Las y los docentes son quienes acompañan a los estudiantes en estas primeras etapas de la vida, siendo partícipes en la construcción de identidades, no sin dejar fuera sus propias subjetividades y creencias. Mediante las representaciones sociales se pretende visibilizar las concepciones que tienen las y los docentes sobre la igualdad de género como un eje transversal en el sistema educativo.

El género, al igual que otros temas como la pobreza, la violencia y el medio ambiente, se han convertido en discursos centrados en las estrategias político-educativas implementadas de forma transversal y apoyadas en cierta medida por los gobiernos con la finalidad de dar respuesta a las problemáticas sociales más urgentes. En ese sentido, nuestro país no es la excepción, puesto que el actual gobierno del presidente Enrique Peña Nieto establece dentro del Plan Nacional de Desarrollo (PND), la inserción de la perspectiva de género como un eje transversal en las dependencias gubernamentales y por ende en el sistema educativo.

\section{PLANTEAMIENTO DEL PROBLEMA}

La idea de crear conciencia en cuanto a la igualdad de género en el ámbito público y privado de las mujeres y los hombres. Ha sido una lucha de los movimientos feministas que buscan contribuir a mejorar las relaciones individuales y sociales entre géneros. En los centros de trabajo, de socialización y estudio (como la casa y 
la escuela) se propicia que el respeto y reconocimiento por la/el otra/o sea una conducta que permita la adecuada convivencia entre hombres y mujeres buscando la creación de una sociedad más justa e igualitaria para todos.

En nuestro país, desde el año 2007 se está trabajando en diversas áreas del ámbito educativo con modelos de equidad de género, abarcando no solo el aspecto de la enseñanza, sino también el de la interacción entre directivos, administrativos, docentes y alumnos. Se busca con ello lograr relaciones de equidad e igualdad entre géneros, visibilizar a la mujer y reconocerle derechos que antes le habían sido negados o anulados. Es en la administración presidencial de Enrique Peña Nieto que la perspectiva de género se plantea como uno de los tres ejes transversales que se deberán insertar en las cinco líneas de trabajo del PND, que son México en paz, México incluyente, México próspero, México con responsabilidad global y en el rubro que particularmente interesa a esta investigación, México con educación de calidad (PND, 2013). El Diario Oficial de la Federación publica en 2013 el PND que sugiere cómo y qué aspectos se deben realizar de manera transversal o directa en cuestiones de género. Las otras dos líneas trasversales son "democratizar la productividad" y "gobierno cercano y moderno".

La enseñanza transversal de la igualdad de género se plantea para la educación básica asumiendo que existe ya una plataforma y estructura que permite a las y los docentes tener todos los elementos para seguir los lineamientos establecidos por el PND. Sin embargo, en las primeras revisiones a los organigramas de la Secretaría de Educación Pública (SEP) no se encuentra una dependencia especializada en cuestiones de género y educación (Organigrama SEP, 2013). En el entendido de que la implementación de la igualdad de género de manera transversal en la educación es una propuesta nueva y existe ya un planteamiento del modelo de igualdad, es necesaria la realización de un diagnóstico de las realidades regionales, en cuanto a la percepción de la igualdad de género aplicada de manera transversal en la educación básica.

Las y los docentes son la base de este proyecto, mientras que los alumnos y alumnas son los que recibirán de manera directa 
los resultados de una óptima o deficiente aplicación de los modelos de igualdad de género.

El género como categoría de análisis por lo general se plantea en vinculación con problemáticas y fenómenos como la violencia y la subordinación. En el ámbito educativo, hasta hace pocos años esta temática estaba desvinculada de los contenidos curriculares, la formación docente y los materiales. En México, es a partir del $2007^{1}$ cuando se plantea el primer modelo de equidad de género. Considerando que los espacios educativos pueden ser la brecha que permita incursionar o propiciar relaciones más equitativas, se plantea la presente investigación con el fin de abonar a la comunidad escolar un análisis sobre perspectiva de género.

El motivo por el cual se realiza en el nivel básico es en virtud de que ahí está uno de los primeros espacios de socialización fuera del hogar, y esta etapa de formación puede dar la pauta a implementar acciones e ideologías que permitan relaciones de convivencia sanas. Es importante que se pueda generar una cultura de respeto entre los géneros desde edades tempranas para que estas nuevas generaciones puedan gozar de una interacción armoniosa.

Sin duda alguna las y los docentes son actores principales al estar como guías en los procesos formativos de las niñas y los niños. Son seres integrales que no pueden dejar fuera del aula sus subjetividades, creencias o simbolismos. Es por esto que las representaciones sociales como constructo teórico y metodológico pueden proporcionar un panorama de cómo el gremio docente visualiza la igualdad de género y la transversalidad. Dependiendo de las representaciones sociales que poseen, es como se conducen en el tema.

Arias y Molano (2010) señalan que las representaciones sociales han trascendido de la ciencia y las teorías a espacios concretos como las aulas. En la educación resulta relevante la incidencia que pueden tener las cuestiones de género "(como resultado de las representaciones sociales que va elaborando un grupo en

1 El Modelo de Equidad de Género es parte del Programa de Certificación sobre Equidad de Género del Instituto Nacional de las Mujeres, desarrollado en 2003 e implementado en el Plan Nacional de Desarrollo 2007-2012. 
el contexto específico del aula de clase) en la configuración de posturas autónomas sobre el asunto o, en algunas circunstancias, seriamente direccionadas por posiciones de grupo, aunque ingenuas" (pp. 12-13).

Dentro del escenario educativo, el rol del docente resulta de gran relevancia, incluso se pudiera considerar fundamental, ya que no solo se requiere de sus conocimientos y su proactividad para que los estudiantes aprendan u obtengan una información en concreto, sino que también se requiere de su comprensión en los asuntos de género desde un contexto macro a un contexto microsocial, especialmente lo que concierne a lo educativo, en este caso particular el género vinculado con las cuestiones de equidad, autonomía y diversidad, con el fin de superar fundamentalismos que tienen sus orígenes en ideologías obsoletas o religiosas.

\section{REPRESENTACIONES SOCIALES}

Como herramienta de investigación, las representaciones sociales (RS) han adquirido mayor relevancia por su riqueza metodológica, que ha tenido sus orígenes en la psicología social, la sociología y la antropología. Las ciencias sociales y la educación han encontrado en las Rs una herramienta teórico-metodológica que logra abarcar desde los espacios de la vida cotidiana de los actores o sujetos de estudio hasta su entorno cultural y su quehacer social.

Durkheim, citado en Moscovici (1979), es el primero en concebir la noción acerca las representaciones colectivas. Con ellas logra identificar el fenómeno social que permite a los individuos construir una idea colectiva a partir de sus representaciones individuales. Así explica cómo un concepto se vuelve universal, permanece en el tiempo y, aunque forma parte del ideario de un determinado grupo social, no necesariamente significa que sea una idea personal. Moscovici retoma a Durkheim y agrega un elemento enriquecedor a esta conceptualización, convirtiendo a las representaciones sociales no solo en una teoría, sino dotándolas de una metodología propia que permite conocer las interacciones entre los actores, sus actividades cotidianas y las ideas que se forman respecto de ellas (1979). 
Ramos (2006) explica cómo Moscovici se interesa por saber qué imagen tienen los ciudadanos comunes, los cuales no están familiarizados con los consultorios de los especialistas en psicoanálisis, pero utilizan términos del mismo, dándoles otro significado de manera colectiva. Es así como recurre a Abric y su concepto de representación colectiva y lo reformula como representación social (RS), generando una teoría dentro de la psicología social sin perder su perfil sociológico, simbólico e histórico.

Ibañes, en Ramos (2006) establece la diferencia entre las RS y la ideología, pues mientras esta última es un fenómeno general y da lugar a un código para interpretar, es decir genera juicios de valor, percepción o actitud sobre un objeto, esta solo es fuente de origen de las Rs, las cuales la pueden modificar, ya que las Rs remiten a un objeto en particular y son construidas por sujetos determinados socialmente, ya sea de manera individual o colectiva. Durkheim, citado en Moscovici (1979), plantea que una idea colectiva se vuelve una idea social; retoma esta idea y la amplía hasta llegar a la conceptualización de las Rs como: "...un corpus organizado de conocimientos y una de las actividades psíquicas gracias a las cuales los hombres hacen inteligible la realidad física y social, se integran en un grupo o en una relación cotidiana de intercambios, liberan los poderes de su imaginación" (Moscovici, 1979, pp. 17-18).

En este mismo sentido, para Abric (2001) las Rs son concebidas como "conjuntos sociocognitivos, organizados de formas específicas, y regidos por reglas propias de funcionamiento" (p. 13), e identifica cuatro funciones de las Rs vinculadas con las prácticas y las interacciones sociales. Estas son:

1. Funciones de saber: permiten describir y explicar la realidad y comunicarla. Por ello constituyen un marco que favorece los intercambios y la comunicación social.

2. Funciones identitarias: las representaciones sociales posibilitan a la vez la construcción de una imagen de sí en el grupo y del grupo en relación con los otros y un conjunto de valoraciones positivas al respecto. 
3. Funciones de orientación: producen una anticipación que actúa como filtro de la interpretación de los acontecimientos de acuerdo con la representación existente y prescriben las prácticas en medios determinados.

4. Funciones justificadoras: además de operar a priori de las situaciones actúan, también, luego de la acción con el fin de perpetuar la posición del grupo.

Estos planteamientos permiten conocer la naturaleza de las concepciones que poseen los sujetos de estudio, la forma y la prioridad organizativa que dan a dichas ideas y cómo las vivencian en cada ámbito de su vida cotidiana.

Para efectos del proyecto realizado, una de las primeras consideraciones fue establecer el campo de la educación como área de trabajo, ya que en los ámbitos profesionales o disciplinarios existe una constante producción de ideas que mantienen una visión común del grupo al que se pertenece (ya sea de clase, cultura o grupo profesional). Jodelet (2011) ubica a las Rs en el ámbito educativo encontrando que "en los campos profesionales, expresa la manera en que los actores se sitúan con relación a su actividad y a sus compañeros, así como frente a las normas y roles vigentes en el espacio de trabajo" (p. 134).

Esta visión ayuda al grupo a tener una concepción de su entorno social, derivando de ello la forma de conducirse en su propio mundo. La experiencia que como individuo se vive día a día en un determinado tiempo y contexto, amén de las situaciones conflictivas que tiene resolver como parte de la vida cotidiana, enriquece y por tanto llega a "afectar el estado de las representaciones y dar lugar a interpretaciones evolutivas, incluso divergentes, en el seno de un mismo grupo social" (Jodelet, 2011, p. 135).

El aporte de Jodelet (2011) resulta conveniente en este caso, cuando plantea que "desde su origen la teoría de las Rs se ha focalizado sobre la relación que mantienen las formas eruditas y científicas del conocimiento y el conocimiento ordinario tal como se despliega en la vida cotidiana bajo la forma del sentido común" (p. 135). En este sentido se reconoce que, entre el proceso de comprensión y asimilación de lo que se aprende científica o 
académicamente y el conjunto saberes con los que los individuos conducen su vida y toman decisiones diariamente, existe una interacción que puede inclinar su actuar hacia la postura que mejor resuelva o dé respuesta a una determinada situación a resolver, ya sea en el ámbito personal o en el de su desempeño profesional.

\section{GÉNERO}

En la actualidad, los estudios de las mujeres muestran al feminismo (entiéndase los feminismos) como movimiento, filosofía política, teoría, forma de activismo y militancia que en un primer momento se utilizó para mostrar interés en mejorar la posición de las mujeres por medios tales como la consecución de derechos políticos, legales o económicos iguales a los que disfrutaban los hombres (Offten \& Ferradis, 1991).

El recorrido de los feminismos se hace en tres grandes etapas marcadas por hitos, autoras que definen teorías en cada una de ellas y aportaciones que propician dar continuidad a las propuestas para identificar las situaciones de invisibilidad, desigualdad y opresión que sufren las mujeres en su entorno social, cultural, político y económico. Valcárcel (2008) define al feminismo como "aquella tradición política de la Modernidad, igualitaria y democrática, que mantiene que ningún individuo de la especie humana debe ser excluido de cualquier bien y de ningún derecho a causa de su sexo" (p. 55). La autora hace la aclaración de que el uso de la palabra "sexo" tiende a cambiarse por el concepto de "género", sobre todo en los últimos años de la producción de teoría que incluye a diferentes grupos con diversas identidades de género que reclaman un reconocimiento a sus derechos y existencia.

El feminismo, al estar en constante recreación, ha ido modificando o replanteando su conceptualización, sus propuestas y exigencias, adaptándose a otros movimientos sociales. Es así como se apropia del género como categoría de análisis, la cual surge en los años 80 a partir de investigaciones psicológicas. Dicho término, en su categoría conceptual como producto de la cultura, conlleva una serie de complicaciones. La primera es que el término anglosajón gender no corresponde de manera puntual a su 
equivalente en español, género. En inglés tiene una acepción que apunta directamente a los sexos (sea como accidente gramatical, sea como engendrar) mientras que en castellano se refiere a la clase, especie o tipo a las que pertenecen las cosas, a un grupo taxonómico, a los artículos o mercancías que son objeto de comercio y a la tela. Decir en inglés "vamos a estudiar género", lleva implícito que se trata de una cuestión relativa a los sexos. En castellano, la connotación de género como una cuestión relativa a la construcción de lo masculino y lo femenino solo se comprende en función del género gramatical (Lamas, 2002, p. 88).

Otra complicación es la que plantea Scott (1996): “...en su acepción reciente más simple, 'género' es sinónimo de 'mujeres'”. En los últimos años, cierto número de libros y artículos cuya materia es la historia de las mujeres sustituyeron en sus títulos mujeres por género.

El género como una de las grandes aportaciones de los feminismos ha tenido diversas conceptualizaciones. Una de ellas plantea que:

En la década de los 80 [...] Por género se entendía una creación exclusivamente social: lo que las representaciones colectivas interpretaban como ser socialmente un hombre o una mujer, es decir, el conjunto de atributos que se asociarían a cada categoría biológica en una determinada cultura: en definitiva, la construcción cultural de lo masculino y lo femenino (Martin, 2006, p. 38).

El abordaje del género en la actualidad no se puede realizar desde esta lógica, pues dentro de la multiculturalidad, las relaciones entre los sexos tienen posibilidades infinitas y el aspecto biológico deja de ser determinante, ya que los "hombres" y las "mujeres" son el resultado de las relaciones sociales; por lo tanto, al modificarse también se cambian las categorías de masculino y femenino (García de León, 1994).

El género como categoría transdisciplinar implica una elaboración histórica de los sistemas de poder, de un discurso hegemónico y patriarcal que no tiene que ver con los sexos, sino con las conductas que se consideran masculinas o femeninas. 
Utilizar la perspectiva de género como referencia en los marcos teóricos de las investigaciones, el diseño de políticas, capacitaciones o programas, requiere reconocer la existencia de las relaciones de poder inherentes en las relaciones de género. También se debe tener en cuenta que el sistema patriarcal favorece principalmente a los varones, creando una subordinación de las mujeres. Otro aspecto a contemplar es que dichas relaciones son el resultado de una construcción histórica y social, y esta a su vez es constitutiva de las personas. Las relaciones de género atraviesan todo el entramado social y se articulan con otro tipo de relaciones, como las de clase, etnia, edad, preferencia sexual y religión (Gamba, 2009).

Flores (2005) apoya el planteamiento anterior, mencionando que: analizar el género implica también entender el contexto y las relaciones sociales, teniendo en cuenta que como sistema simbólico está afectado por el poder. Bajo estas revisiones es evidente que el término de género ha evolucionado drásticamente, dejando de ser un discurso social emergente para convertirse en un medio de análisis, ampliando la visión que definía las acciones de hombres y mujeres respecto a su constitución biológica. El género en la actualidad implica una construcción más amplia que integra aspectos como el contexto, las relaciones sociales, el sistema político-económico. Pero, sobre todo, se reconocen abiertamente las relaciones de poder dentro de las relaciones de género en un sistema patriarcal.

\section{GÉNERO Y EDUCACIÓN}

Acker (2003) realiza un abordaje de la educación desde las distintas perspectivas de las teorías feministas retomando al feminismo liberal, el feminismo socialista y el feminismo radical.

Dentro del feminismo liberal, Acker (2003) plantea la igualdad de oportunidades entre los sexos, por lo cual se propone eliminar los obstáculos que puedan impedir que las estudiantes alcancen su total potencial e independencia en las escuelas.

El feminismo socialista, por su parte, se propone eliminar la opresión, esta postura define tres aspectos principalmente, los 
cuales son la igualdad de oportunidades, la socialización y estereotipos de género, y la discriminación sexual.

El feminismo radical plantea cambios en la estructura social, los cuales son fundamentales para eliminar el dominio del patriarcado. Sus metas no son la igualdad de conocimientos, de poder o riquezas: esta corriente tiene como propósito la erradicación de la cultura opresiva sustentada en el género. Pero dentro de esta corriente se han realizado pocas aproximaciones a la educación y la relación de esta con la economía y la familia.

Para Vega (2007), la escuela es un espacio donde se producen y reproducen los estereotipos de género. Asimismo, se generan procesos de discriminación (sobre todo para las mujeres), donde el trato entre géneros es diferenciado al igual que el acceso a las oportunidades. Al ser la escuela un espacio de socialización donde se determinarán y condicionarán también las relaciones laborales, es necesario introducir una sensibilización social donde los agentes generen nuevas formas de interacción. Esto implica un cambio en el uso del lenguaje androcéntrico, así como la deconstrucción de los esquemas de roles, valores y estereotipos sexistas y discriminadores. Dichos elementos se encuentran presentes de manera directa o indirecta (en el currículo oculto) tanto en los materiales, las prácticas pedagógicas, los contenidos, el uso de los espacios, las actitudes, las conductas y el trato dentro de las instituciones educativas como en su interacción con la comunidad y los padres de familia.

\section{TRANSVERSALIDAD DE GÉNERO}

Para lograr una óptima implementación de la perspectiva de género se ha recurrido a nuevas estrategias político-educativas como la transversalidad de género, la cual pretende incorporar políticas específicas dentro de otras más generales (como la salud, los servicios sociales, el empleo, entre otros). El término gender mainstreaming tiene sus orígenes en la cultura anglosajona y se comenzó a utilizar de manera oficial en la Conferencia Mundial de la Mujer de Naciones Unidas en Beijín, 2005. A partir de entonces se han construido diversas definiciones del mismo. Cabe 
destacar que dicho concepto es resultado de un proceso de globalización, por lo cual puede considerarse como una necesidad de las sociedades en general, pero de igual manera puede ser un arma de doble filo si se convierte solo en un discurso a reproducir por los diferentes gobiernos (Durán, 2012).

La transversalidad del género constituye un enfoque sobre la igualdad de oportunidades entre los sexos que pretende integrar la perspectiva de género en los diversos ámbitos (social, económico y político) de la vida humana y en las esferas públicas y privadas. Surge de las reflexiones, análisis y valoraciones de las prácticas y políticas llevadas a cabo para lograr la igualdad entre hombres y mujeres que han puesto de manifiesto que, si bien se han logrado avances importantes en este terreno, no se está logrando modificar los elementos o factores estructurales que configuran la desigualdad (Munevar \& Villaseñor, 2005, pp. 46-47).

Por su parte, Vega (2007) plantea que la transversalidad es mucho más que sólo incorporar políticas específicas a las diferentes áreas del conocimiento. Una verdadera transversalidad requiere de la reorganización y reestructuración a todos los niveles, es decir, se requiere del compromiso de todas las estructuras políticas, de los procesos de toma de decisiones, de la inclusión en la igualdad de oportunidades y del involucramiento de todos los actores sociales. Todo esto con el fin de incorporar los principios de igualdad de oportunidades tanto de hombres como mujeres.

\section{METODOLOGÍA}

Para la elaboración de un diagnóstico que permita conocer la visión de los y las docentes respecto a la igualdad de género como un eje transversal, se propone la obtención de las representaciones sociales que ellas y ellos poseen sobre estos conceptos. Las representaciones sociales (RS) por sí solas son un cuerpo teóricometodológico completo, concebidas como "conjuntos sociocognitivos, organizados de formas específicas, y regidos por reglas propias de funcionamiento", generando "una visión funcional del 
mundo, que permite al individuo o grupo, conferir sentido a sus conductas, y entender la realidad mediante su propio sistema de referencias y adaptar y definir de este modo un lugar para sí" (Abric, 2001, p. 13).

Debido a que el concepto de género se basa en construcciones sociales que permean todos los ámbitos de la vida pública y privada, a través de las representaciones sociales encontramos una vía por la cual se puede obtener información acerca de la visión que las y los profesores manejan tanto en la práctica profesional como en su vida cotidiana. Una de las consideraciones que se contemplaron para definir nuestro objeto de estudio y su análisis es que el concepto de género se maneja en cohesión con otros términos como la equidad de género y la perspectiva de género. El término a analizar en la presente investigación es el de igualdad de género, ya que es de esta manera como lo establece el PND, como uno de sus tres ejes transversales. Es decir, son los lineamientos oficiales los que delimitan nuestro objeto de estudio en cuestión terminológica. Consideramos necesario identificar si el gremio de docentes tiene claro el término "igualdad de género" y las implicaciones teóricas que este representa, ya que para la aplicación de la igualdad de género como un eje transversal se requiere una comprensión adecuada de la propuesta teórica.

Puesto que el PND tiene dos años de haberse implementado, no es posible por el momento obtener un balance de las propuestas de trabajo en él descritas; sin embargo, en la búsqueda de condiciones para su efectivo funcionamiento deben realizarse acciones que promuevan los cambios necesarios para el logro de los objetivos. Muestra de ello es la creación de la Unidad de Igualdad de Género de la Secretaría de Educación Cultura y Deporte del Estado de Chihuahua.

Pese a que el Plan Estatal de Desarrollo (PED) se encuentra desfasado del Plan Nacional de Desarrollo en tiempo, acciones y terminología, la Unidad de Igualdad de Género, adscrita a la Secretaría de Educación, Cultura y Deporte, trabaja en la investigación, capacitación, promoción y creación de condiciones de igualdad y temas de género para todo el sector educativo en el 
estado, tendientes a cumplir con los objetivos del PND 2013-2018 y el PED 2010-2016.

La investigación nace de la inquietud por conocer cuáles son las condiciones actuales de las y los docentes en cuanto a la concepción y aplicación de los temas de género. Guerra y Guerrero (2004) reconocen tres puntos básicos en la elección del método de investigación que se decide una vez identificado nuestro objeto de estudio y que se derivan uno del otro: a) la adopción de un método no es una decisión arbitraria; b) esta se liga estrechamente al tipo de conceptualización que se formula del fenómeno a estudiar; c) las exigencias e intereses del investigador provienen del contexto subjetivo social y político en que dicho trabajo se produce.

De acuerdo con Abric (2001), la recolección de datos en la metodología de las Rs representa, junto con el análisis de los mismos, uno de los puntos que se identifican como problemáticos para la misma. Por tanto, es necesario elegir una metodología que además de las consideraciones empíricas tenga un sustento y justificación teórica sólida. En este caso, las Rs aportan una teoría propia que nos permite contar con diversas herramientas de recolección, con las que, de acuerdo a cada caso, se puede obtener información de calidad pertinente y válida para captar el objeto de estudio.

Desde la perspectiva teórica de las Rs, estas se dividen en dos componentes: su contenido y la organización o estructura interna. Por lo tanto, el análisis se debe realizar en ambos niveles. Los métodos de las Rs deben identificar y hacer visibles los elementos que constituyen a la representación social, así como la forma en que se organizan dichos elementos, e identificar un núcleo central de la representación.

Para cumplir los objetivos anteriores es necesario contar con una plurimetodología que se organice en tres tiempos sucesivos: primeramente se tiene que identificar el contenido de la representación, luego la relación entre los elementos, es decir su importancia y jerarquía, y posteriormente identificar un núcleo central.

Un acercamiento plurimetodológico es el que nos permite recoger de manera conjunta los tres elementos de las Rs (su contenido, su estructura interna y su núcleo central), pues ninguna otra técnica permite recoger simultáneamente los tres elementos. 
Dicho análisis se plantea en cuatro etapas. La primera implica la recolección de los datos en la cual es indispensable contar con la entrevista, anexando un método asociativo. La segunda busca la estructura y el núcleo central; es en esta etapa donde se organiza y categoriza la información, recurriendo a las técnicas de reagrupamiento. La tercera etapa verifica la centralidad. Y la cuarta se enfoca en el análisis de la argumentación, es decir, tiene que llegar a evidenciar la estructura interna y el núcleo central de la RS, así como la forma en que se llega a un discurso argumentado (Abric, 2001).

El objetivo general de la investigación pretende dar cuenta de que la búsqueda está encaminada a las Rs de la igualdad de género, así como del mecanismo con que esta es insertada en el sistema educativo; en este caso, como un eje transversal. Cabe destacar que después de un ejercicio exploratorio y un piloteo, el término se neutralizó de manera que diera un margen más amplio a los sujetos para expresar su concepción sobre esta estrategia, donde finalmente se optó por el término transversalidad.

Nuestro objetivo general es visualizar las representaciones sociales que tienen las y los docentes de preescolar y primaria en el estado de Chihuahua sobre la igualdad de género como un eje transversal en el sistema educativo.

Para esta investigación se eligen tanto el método asociativo como el interrogativo. Para el primero se utiliza específicamente el de la asociación libre con el término de igualdad de género, y luego otro con el término de transversalidad, el cual se funda en una producción verbal. Dicho método consiste en tener uno o varios términos inductores y solicitarle al sujeto que genere todos los adjetivos, expresiones o conceptos como le sean posibles. La ventaja de este método es que es más rápido y fácil en comparación con la entrevista, por menos controlado, dejando margen a la espontaneidad del ser. Con este método se pretende dar respuesta a los dos primeros objetivos de investigación: visualizar las representaciones sociales que tienen las y los docentes de preescolar y primaria en el estado de Chihuahua sobre la igualdad de género y visualizar sus representaciones sociales sobre la transversalidad. 
El método interrogativo utilizado fue la entrevista, con la cual se pretende dar respuesta al tercer objetivo específico: visualizar las concepciones y percepciones de las y los docentes en relación con su forma personal de instrumentar la igualdad de género como un eje transversal en el sistema educativo.

En las RS, el instrumento siempre debe contar con los siguientes elementos: presentación, instrucción y tabla sociodemográfica. Además, cada instrumento puede tener varias preguntas de representación, una jerarquía (que responde a la forma de organizar la Rs) y un complemento (preguntas abiertas para analizar contenido de las Rs).

Con la posibilidad que brinda el instrumento asociativo de RS proporcionado y adaptado para esta investigación, se pretende hacer un abordaje tanto cuantitativo como cualitativo. En este caso se constituye primeramente por una tabla de asociación libre, la cual brinda un enfoque cuantitativo que nos arroja la matriz de proximidad, y un árbol de conceptos para finalmente llegar al esquema de núcleo-periferia de las Rs de los docentes, triangulándose con la parte cualitativa (entrevista aplicada en la segunda parte del instrumento).

Creswell (2009) argumenta en favor del uso de la metodología mixta y los diseños multimodales, pues la investigación requiere cada vez más del trabajo conjunto de diversos investigadores, siendo posible realizar el trabajo en equipos conformados por personas con diversas visiones sobre un mismo tema y usando tanto la metodología cuantitativa como la cualitativa.

Considerando lo que refiere Creswell en Hernández (2010) acerca de la posibilidad de que "ciertos datos cualitativos pueden incorporarse para describir un aspecto del fenómeno que es muy difícil de cuantificar", se busca que los datos cuantitativos obtenidos del instrumento asociativo de Rs se triangulen con los obtenidos en la segunda etapa, a fin de complementar y reforzar lo que las y los docentes expresen como sus representaciones sociales sobre la igualdad de género y su aplicación transversal en la educación preescolar y primaria. 
Para realizar los ajustes pertinentes al instrumento, así como la validación, se realizó el piloteo en preescolares y primarias de Ciudad Juárez validando por grupos de pares y expertos.

El sistema educativo de Chihuahua agrupa en diversos conceptos a las escuelas de educación básica, dependiendo del tipo de servicio, sostenimiento, dependencia normativa y dependencia administrativa al que estén adscritas. Los subsistemas federado y estatal son los dos grandes grupos en los que se dividen y que determinan, en un momento dado, tipo de capacitación, evaluación y prestaciones que reciben los docentes de uno y otro grupo. El grupo perteneciente al subsistema federal congrega a grupos con características específicas, como las escuelas de educación especial, educación indígena, educación para adultos y escuelas privadas, entre otras; esto deriva en una gama de condiciones especiales para el gremio de docentes que atienden este tipo de escuelas. Mientras que el subsistema estatal se conforma por escuelas que ofrecen un servicio general, los docentes de este grupo en particular guardan un perfil más homogéneo del total maestras y maestros del estado.

La selección de la muestra fue conformada por el sector de docentes de preescolar y primaria del subsistema Estatal del estado de Chihuahua, estadísticamente representativo de la entidad y adecuada a la metodología de las representaciones sociales. Los docentes estaban en servicio y frente a grupo al momento de aplicar el instrumento.

Para la recolección de datos fue muy importante la gestión. En este caso, la población es numerosa y dispersa en el estado de Chihuahua, motivo por el cual se requería el consentimiento de los sujetos involucrados directamente, así como también de las autoridades pertinentes. Debido a ello se realizaron acercamientos al Departamento de Investigación y la Unidad de Igualdad de Género, quienes fueron intermediarios entre nuestra investigación y la Dirección General de Educación, para que se autorizara nuestra intervención con las y los docentes.

Se visitó un total de 46 escuelas en el nivel preescolar, mientras que para primarias, el total fue de 26 instituciones educativas de 
los municipios de Ahumada, Chihuahua, Gómez Farías, Jiménez, Madera, Matachic, Nuevo Casas Grandes y Parral.

El número de escuelas visitadas para el levantamiento de datos respondió a la necesidad de recabar los 250 cuestionarios de corte cuantitativo para cada nivel establecidos en la metodología, con el fin de llegar a la saturación de los datos sugerida por las Rs.

Para la sistematización y el análisis de la información se contemplaron los datos cerrados, en este caso los términos expresados por los y las docentes, y los datos abiertos de la entrevista con los que se generan argumentos pivote.

\section{RESULTADOS PRELIMINARES}

A manera de resultados preliminares se presenta la información obtenida de las entrevistas a las y los maestros que accedieron a compartir sus impresiones acerca de la igualdad de género y sus concepciones sobre transversalidad, así como los datos estadísticos resultantes de las muestras recolectadas en preescolar y primaria.

Un aspecto que resalta estadísticamente en el nivel preescolar es la marcada feminización de la carrera docente, donde maestras de grupo y directoras representan casi el cien por ciento del gremio en este nivel escolar. Es notoria la segregación por género en el grupo de maestros (hombres). Se cuentan los que imparten las asignaturas de inglés, música y deportes; solo uno de ellos era maestro permanente frente a grupo. Caso contrario, solo se cuenta con una maestra impartiendo Educación Física entre las maestras y maestros de la muestra recolectada (Gráfica No. 1).

González, en Bustillos y Rincones (2014), hace una reflexión histórica del cuidado de la infancia y cómo este recae en las mujeres por la concepción que se tiene de ellas como madres, mismas que son quienes cuidarán con amor a los hijos, sobre todo en las edades más tempranas, cuando los niños requieren mayor atención y cuidados. Con el paso del tiempo y el ingreso de las niñas y niños a la escuela cada vez a edades más tempranas, se espera que la transición de la educación en casa al preescolar se haga con la misma figura de amor, de ahí que se refuerce la idea 
de la imagen femenina como la ideal para el cuidado de los más pequeños integrantes del sistema de educación básica.

Gráfica 1. Distribución por género en preescolar

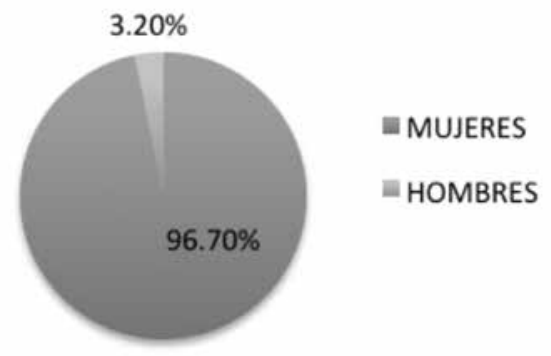

Para el nivel preescolar, los rangos de edad encontrados van de los 21 a los 45 años en hombres, mientras que para mujeres el resultado arroja un dato de 22 a 62 años. En cuanto a los años de servicio, la muestra incluye docentes con 6 meses de estar laborando y hasta 32 años. Las maestras registraron de 9 meses a 32 años de servicio.

La mayor concentración de escuelas del subsistema estatal preescolar se encuentra en la ciudad de Chihuahua, seguido de Ciudad Juárez; el resto se distribuye en el estado. Cabe mencionar que particularmente en Ciudad Juárez se encontraron instituciones educativas con solo una maestra frente a grupo y la directora del plantel. Esto ocurre sobre todo en las áreas de la ciudad que poco a poco se han quedado despobladas o en las zonas más antiguas, como ocurre con la zona centro. En las áreas con mayor población, los planteles cuentan con hasta ocho grupos, cubriendo segundo y tercer grado.

En caso de tener espacio disponible en la infraestructura y previa autorización de la Secretaría de Educación, se abren grupos de primer grado. Esto para el caso de los planteles que tienen mayor demanda. Mientras tanto, las escuelas con poca población esperan cada año a ver la cantidad de alumnos inscritos para poder continuar o en determinado momento cerrar la institución. 
Gráfica 2. Distribución por género en primaria

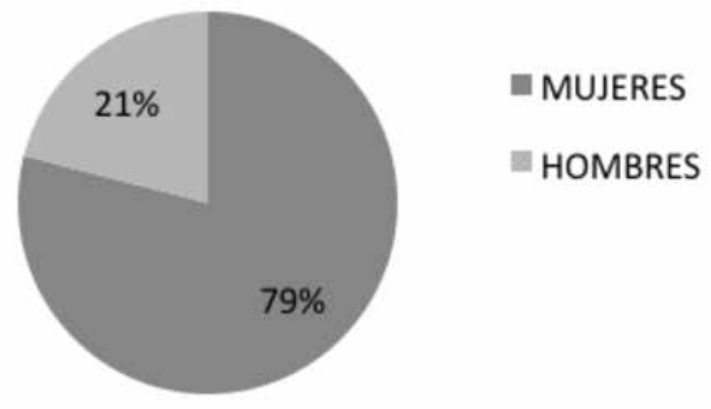

A diferencia de preescolar, en el nivel primaria vemos una mayor participación porcentual de maestros, sin embargo, el número de maestras los supera considerablemente. La tendencia de encontrar más hombres que mujeres en la asignatura de educación física sigue marcada en este nivel educativo, repitiéndose la misma situación que en preescolar. Respecto a las edades de los encuestados encontramos profesores entre los 22 y 61 años; las profesoras se encuentran entre los 20 y 63 años de edad. En el renglón de años de servicio, los hombres están en el rango de los 7 meses a los 36 años de ejercicio de su profesión. Las mujeres están entre los 4 meses y los 33 años (Gráfica No. 2).

El nivel primaria mantiene su matrícula para por lo menos un grupo por grado escolar, además de contar al interior de las mismas con educación especial a cargo del Centro de Atención Múltiple (CAM). De igual manera, la concentración que se menciona de preescolares en la ciudad de Chihuahua se repite para primaria, siguiendo en número Ciudad Juárez. El resto se distribuye en las demás ciudades visitadas.

Respecto a la información que las y los docentes brindaron de sus Rs sobre la igualdad de género, rescatamos que el concepto con el cual ellas y ellos lo asocian es con el de equidad de género, definiendo a este último como la equiparación de condiciones, oportunidades y derechos.

El que se contemple este y no otro término tiene implicaciones teóricas, las cuales se reflejan en acciones concretas. En este sen- 
tido, se retoma la teoría de las Rs, la cual se plantea dependiendo de lo que se construya o se piense sobre algo. Esto nos llevará a actuar de una manera específica.

Los y las docentes en su mayoría realizan acciones encaminadas a lograr condiciones de igualdad de género de manera transversal, aunque como ellos mismos lo reconocen, hace falta realizar muchas más, las cuales tienen contempladas de una manera clara y concreta.

El término de transversalidad resultó más complejo para el gremio docente. En términos generales, se pudo brindar una concepción técnica del mismo, aunque con una notoria cerrazón a opinar o expresar sus concepciones sobre el concepto.

Cabe destacar que las y los docentes manifestaron su preocupación por extender la concientización de las condiciones de igualdad hasta el ámbito familiar, ya que como ellos y ellas lo expresaron, los padres de familia a menudo constituyen sus mayores retos.

La recepción que se tuvo por parte de las y los directivos de las instituciones educativas visitadas se dio en un ambiente de gran colaboración con el proyecto de investigación. Pero, sobre todo, la comunidad docente a lo largo y ancho del estado de Chihuahua mostró un gran interés por la temática y por conocer los resultados que deriven de este ejercicio; de ahí el compromiso de presentar resultados que puedan colaborar con la elaboración de estrategias de capacitación y sensibilización en la perspectiva de género.

\section{REFERENCIAS}

Abric, J. (2001). Prácticas sociales y representaciones. México. Ediciones Coyoacán.

Acker, S. (2003). Género y educación: reflexiones sociológicas sobre mujeres, enseñanza y feminismo. España. Narcea.

Arias, J. y Molano, P. (2010). Representaciones sociales de género en el contexto educativo rural. latinoam.estud.educ. 6 (2): 11-35. Recuperado de: http://www.redalyc.org/articulo.oa?id=134126048002

Banco Interamericano de Desarrollo (2004). Los objetivos del desarrollo del milenio en América Latina y el Caribe. Retos, acciones y com- 
promisos (361.25 O722-dc21) Washington, D.C. Recuperado de: http:// www.cepal.org/mdg/docs/IADBPublicDoc.pdf

Bustillos, S. y Rincones, P. (2014) Políticas públicas: cuidado e infancia. México. El Colegio de Chihuahua.

Camacho, L. y Watson, H. (2008). Reflexiones sobre la equidad de género y educación inicial. InterSedes: Revista de las Sedes Regionales, vol. VIII, núm. 14, 2007, pp. 33-48. Universidad de Costa Rica. Recuperado de: http://www.redalyc.org/articulo.oa?id=66615071004

Creswell, J. W. (2009). Research design: qualitative, quantitative, and mixed approaches. Thousand Oaks, CA. Sage.

Diario Oficial de la Federación (2013). Plan Nacional de Desarrollo 20132018. Distrito Federal, México. Diario Oficial de la Federación. Recuperado de: http://www.dof.gob.mx/nota_detalle.php?codigo=529946 $5 \&$ fecha $=20 / 05 / 2013$

Durán, M. (2012). La transversalidad de género en la educación superior: propuesta de un modelo de implementación. Posgrado y Sociedad, vol. 12, núm. 1, 23-43. Recuperado de: http://web.ua.es/es/unidad-igualdad/documentos/transversalidad-genero-educacion.pdf

Flores, B. (2005). Violencia de género en las escuelas: sus efectos en la identidad, en la autoestima y en el proyecto de vida. Revista Iberoamericana de Educación N.․ 38. (p. 27-46).

Gamba, S. (2009). Diccionario de estudios de género y feminismos. Buenos Aires. Biblos.

García de León, M. A. (1994). Élites discriminadas: sobre el poder de las mujeres. Barcelona. Anthropos.

Guerra, M. y Guerrero, M. (2004). ¿Qué sentido tiene el bachillerato? Una visión desde los jóvenes. México. Universidad Pedagógica Nacional.

Hernández, R., Fernández, C. y Baptista P. (2010). Metodología de la investigación. México. Mc Graw Hill.

Jodelet, D. (2011). Aportes del enfoque de las representaciones sociales al campo de la educación. Espacios en blanco -Serie Indagaciones- $\mathrm{N}^{\circ}$ 21-junio 2011 (133-154). Recuperado de: http://www.scielo.org.ar/ scielo.php?script=sci_pdf\&pid=S1515-94852011000100006\&lng= es\&nrm=iso\&tlng=es\#

Lamas, M. (2002). Cuerpo: diferencia sexual y género. México. Taurus.

Martín, A. (2006). Antropología del género: culturas, mitos y estereotipos sexuales: feminismos. Madrid. Ediciones Cátedra. 
Munévar, D. I. y Villaseñor, M. L. (2005). Transversalidad de género. Una estrategia para el uso político-educativo de sus saberes. Revista de Estudios de Género. La Ventana (21) 44-68. Recuperado de http://www. redalyc.org/articulo.oa?id=88402102

Moscovici, S. (1979). El psicoanálisis, su imagen y su público. Buenos Aires. Editorial Huemul, S. A.

Naciones Unidas (1995). Declaración y plataforma de acción de Beijing. Recuperado de: http://www.un.org/womenwatch/daw/beijing/pdf/ BDPfA\%20S.pdf

Naciones Unidas (1995). Informe sobre la cuarta conferencia mundial sobre la mujer. (A/CONF.177/20/Rev.1) Nueva York. Recuperado de: http:// www.un.org/womenwatch/daw/beijing/pdf/Beijing\%20full\%20report\%20S.pdf

Offten, K. \& Ferradis, M. (1991). Definir el feminismo: un análisis histórico comparativo. Historia social, N. 9 (verano, 1991). Pp. 103-135. Fundación Instituto de Historia Social. Recuperado de: http://www.jstor. org/stable/4034055

Ramos, J. (2006). Identidad socioétnica de maestros-indígenas-mixtecos (tesis doctoral). México, D.F. Escuela Nacional de Antropología e Historia.

Secretaría de Relaciones Exteriores (2005). Camino a la igualdad de género en México: propuestas (Proyecto MEX/03/003 (00013587). Seguimiento de los compromisos internacionales de México en materia de derechos humanos de las mujeres y fortalecimiento de la perspectiva de género en la Secretaría de Relaciones Exteriores. Recuperado de http://www. sre.gob.mx/images/stories/docsdh/igualdad/igualdaddegnero.pdf

Scott, J. (1996). El género: una categoría útil para el análisis histórico. En El género: la construcción cultural de la diferencia sexual. Martha Lamas (coord.) México. PUEG. Pp. 265-302.

Valcárcel, A. (2008). Feminismo en el mundo global. Madrid. Cátedra. Vega, A. (2007). Mujeres y educación. Una perspectiva de género. Málaga. Aljibe. 